\title{
Analysis of the Non-Financial Information Disclosed by the Bulgarian Thermal Power Plants
}

\author{
Chief Assistant Professor, PhD Tsvetomir Manolov \\ University of Economics - Varna, Varna, Bulgaria \\ wt_varna@ue-varna.bg
}

\begin{abstract}
Presentation of environmental and social aspects of enterprises' activities is usually done by disclosing of nonfinancial information. It is possible to be realized as a part of the annual financial statement, as an element of the activity report, through other reports or websites of the companies. This article examines how such information is disclosed of three of the largest Bulgarian thermal power plants. The results of the study are summarized through a table, and the corresponding conclusions are formulated.
\end{abstract}

Keywords: non-financial information, disclosure, thermal power plants

JEL Code: M41, Q56 DOI: https://doi.org/10.36997/IJUSV-ESS/2020.9.3.136

\section{Въведение}

Целта на нефинансовата информация, публикувана от топлоелектрически централи в България, е да представи пред заинтересованите лица данни и показатели, относно целите и резултатите от дейността им по отношение на всички съществени въпроси, свързани найвече със социалните и екологичните им дейности, а така също и с правата на човека и борбата с корупцията.

Обичайно тази информация е свързана с дейността на предприятието в контекста на социалната отговорност и устойчивото развитие, като има за цел да разкрие постигнатите резултати в тези насоки. Тъй като няма строго определена форма относно начина, по който тази информация се представя пред обществото, предприятията често избират различни формати и прилагат различни методики и стандарти за оповестяване на нефинансовата информация. Към настоящия момент основното средство използвано за разкриване на подобен тип информация е нефинансовата декларация, но е възможно това да се прави и като се използват самостоятелни отчети, верифицирани доклади и интернет сайтовете на дружествата.

В тази връзка целта на настоящата статия е да се анализира както съдържанието на нефинансовата информация, разкривана от топлоелектрическите централи в България, така и начина по който това се прави.

\section{1. Обхват и методология на проучването.}

Предвид факта, че една значима част от публикуваната нефинансова информация е с екологична насоченост, то същата е използвана като основен критерий, по който са селектирани предприятията, обект на проучване.

На база на третия национален план за действие по изменение на климата за периода 2013 - 2020 г. (Министерство на околната среда и водите,2012) в България е изследвано моментното състояние на емисиите от парникови газове и е установено, че парниковите газове, за които е отговорен сектор „Енергетика“, са с най-голямо и нарастващо участие в общите емисии, което определя тяхната първостепенна важност за изпълнението на националните цели за намаляването им.

Съгласно направено от автора проучване на верифицираните доклади пбликувани на сайта на Изпълнителна агенция по околна среда (ИАОС, 2020) бе установено, че през 2019 г. в България са верифицирани 29194151 тона емисии на парникови газове. От тях 17812878 тона или $61 \%$ са емитирани от три кондензационни топлоелектрически 
централи.

В резултат на това в окончателната извадка на изследването попадат 3 дружества. От тях единствено „Марица Изток 2” ЕАД (1 $604 \mathrm{MW}$ ) е държавна компания в състава на „Български Енергиен Холдинг“ ЕАД, докато останалите - ТЕЦ „Контур Глобал Оперейшънс България” (908 MW), „Ей И Ес-3С Марица Изток 1” (686 MW), са изцяло или преобладаващо частна собственост.

\section{Емпиричното проучване е проведено при спазването на следната методология:}

- определени са предприятията, които са отговорни в най-голяма степен за емитираните парникови газове;

- на базата на съществуващата нормативна уредба в Република България и Директива 2014/95/ЕС, относно оповестяването на нефинансова информация и на информация за многообразието от страна на някои големи предприятия и групи (Официален вестник на Европейския съюз, бр. L 330/1 от 15.11.2014 г.), авторьт е извел критерии, по които да бъде обследвана оповестяваната от дружествата нефинансова информация. Съставен е чеклист, в който най - общо са обособени 4 раздела, както следва:

1. Наличие на информация с екологична насоченост;

2. Наличие на информация за социални дейности;

3. Наличие на информация за правата на човека;

4. Наличие на информация за борбата с корупцията.

- извършен е анализ на годишните финансови отчети на предприятията за 2019 г., пуликувани в Търговския регистьр (Търговски регистьр, 2020), на различните доклади, които те изготвят, както и на оповестената на сайтовете им информация.

Всичко това позволява да се анализира нефинансовата информация, която изследваните дружества оповестяват и да се извърши съпоставка между тях.

2. Проучване и анализ на нефинансовата информация, оповестявана от топлоелектрическите централи в България

Резултатите от проведеното проучване са представени в обобщена таблица, с помощта на която е направен опит да се онагледят и обобщят постигнатите резултати. В нея всяко едно от изследваните предприятия е номерирано, както следва:

1- ЕЙ И ЕС - ЗС Марица изток І ЕООД;

2- ТЕЦ Марица изток 2 ЕАД;

3- Контур Глобал Марица изток 3 АД;

Те са систематизирани на база източниците на информация - годишен финансов отчет, годишен доклад за дейността или уеб сайт на съответното предприятие и са оценени по вече посочените по-рано в разработката критерии.

2.1. В резултат от направеното изследване на ТЕЦ "ЕЙ И ЕС - ЗС МАРИЦА ИЗТОК І" ЕООД за 2019 г. се установи, че:

- По отношение на информацията с екологична насоченост

- През изследвания период в годишния финансов отчет е оповестена информация за пет от седемнадесетте изследвани критерия. По тази причина може да се твърди, че дружеството оповестява недостатъчен обем информация.

Представени са данни, че е сключен договор за извозване на генерираните от централата отпадъци в специализирано депо на дружество, свързано лице на разглежданото. Предприятието посочва размера на разходите за изхвърляне на отпадъците в хиляди лева в бележките към годишните си финансови отчети, както и вида и стойностния размер на използваните горива за производството на електроенергия. 
По отношение на разходите за покупка на квоти, за през 2019 година дружеството оповестява в стойностен размер закупените квоти, както и размера на неизплатеното задължение към доставчиците на квоти в своите тьрговски задължения.

В разглеждания отчет ясно е декларирано, че предприятието няма правни или конструктивни задължения, свързани с опазването на околната среда, не са създадени провизии за дължимите квоти за изпуснати парникови емисии, докато същевременно са посочени разходи за закупуване на квоти.

- За изследваният период в годишните доклади за дейността е оповестена информация за единадесет от седемнадесетте критерия. .

- През изследваният период в уеб сайта на предприятието (https://aes.bg) е оповестена информация за девет от седемнадесетте изследвани критерия. Проучването показва, че то има изградени редица съоръжения за мониторинг на емисиите и очистителни инсталации, а именно:

- Система за непрекъснат мониторинг на емисиите;

- Сероочистваща инсталация за димни газове;

- Автоматична измервателна станция;

- $\quad$ Пречистване на отпадни води;

- $\quad$ Съорьжение за депониране на отпадъци.

ТЕЦ "ЕЙ И ЕС - ЗС МАРИЦА ИЗТОК І" ЕООД декларира, че дейността му е в съответствие с всички законови изисквания, производственият процес осигурява оптимално управление на всички компоненти на околната среда при пълно спазване на европейското законодателство и най-добрите практики, включително Директива 2001/80/EC за ограничаване на емисиите, изпускани от големите горивни инсталации (Официален вестник на Европейския съюз, бр. L 309/1 от 27.11.2001г.) и е готова да отговори на по-строгите изисквания на Директива 2010/75/EC, относно емисиите от промишлеността (комплексно предотвратяване и контрол на замърсяването) (Официален вестник на Европейския съюз, бр. L 334/17 от 17.12.2010 г.).

В резултат на това може да се направи извода, че дружеството оповестява сравнително голям обем описателна информация за въздействието му върху околната среда. Въпреки това могат да се посочат и следните слабости:

- липса на информация за размера на направените инвестиции в екологични съоръжения;

липсата на достатьчна детайлно оповестяване на изпуснатите емисии парникови газове, доколко те превишават безплатно разпределените квоти от държавата, защо не се отчита провизия за необходимите за закупуване допълнителни квоти и други;

Може да се заключи, че оповестената екологична информация от ТЕЦ "ЕЙ И ЕС - ЗС МАРИЦА ИЗТОК I" ЕООД за 2019 г. година е недостатъчна за задоволяването на интересите на потребителите - както вътрешни, така и външни. Оповестените екологични данни са с преобладаващо общ характер, със сравнително малко уточнения и разяснения и трудно биха се използвали, за да се изгради представа за политиката за управление на околната среда и бъдещото развитие на дружеството в този така важен аспект от дейността му.

\section{- По отношение на информацията за извършваните социални дейности}

Информация за тези дейности се съдържа единствено в уеб сайта на компанията, където сравнително подробно са описани политиката на осигуряване на здравословни и безопасни условия на труд, предприети действия за осигуряване на равенство между половете и извършваните обучения на персонала. Това до голяма степен се дължи и на факта, че след 2016 година., дружеството няма персонал.

\section{- По отношение на информацията за правата на човека}

Информация за тези дейности се съдържа единствено в уеб сайта на компанията, което до голяма степен се дължи и на факта, че след 2016 година, дружеството няма 
персонал

- По отношение на информацията за борбата с корупцията

Дружеството не оповестява подобна информация.

2.2. На база на извършеното изследване по отношение на ТЕЦ „Марица изток 2“ ЕАД по определените критерии за 2019 година се установи че:

- По отношение на информацията с екологична насоченост

- през 2019 г. в годишните финансови отчети е оповестена информация за пет от седемнадесетте изследвани критерия. Най-подробни са оповестяванията по отношение на начислените от дружеството провизии за недостиг на квоти за емисии на парникови газове които представляват разликата между реално емитираните, верифицирани количества и безвъзмездно предоставените по Националния план за инвестиции на Република България за периода 2013 г. - 2020 г.

- За изследвания период в годишните доклади за дейността е оповестена информация за седем от седемнадесетте критерия, което предвид задължението на дружеството да изготвя като част от доклада за дейността си и нефинансова декларация означава, че публикуваната информация е в минималния изискван от закона обем.

Съпоставката на двата източника показва, че независимо от факта, че предприятието заявява цялостно съответствие на дейността си с действащото законодателство, като посочва наличието на необходимите лицензи и разрешителни, оповестява неустойки по договор Санкции за нарушена екология. Според нас би било полезно за потребителите да бъде разкрита по-детайлна информация за конкретните случаи, за да има яснота в политиката по опазване на околната среда на дружеството.

.- През изследваният период в уеб сайта на дружеството (https://www.tpp2.com/) е оповестена информация за осем от седемнадесетте изследвани критерия. Като цяло впечатление прави, че на своя уеб сайт предприятието разкрива предимно нефинансова екологична информация с описателен характер, засягаща отделните проекти за изграждане на съоръжения и обекти с екологичен характер и наличните системи за мониторинг и контрол на състоянието на околната среда, в резултат на влиянието на упражняваната от дружеството дейност.

- По отношение на информацията за извършваните социални дейности

Дружеството оповестява подробна информация по отношение на извършваните социални дейности, което е резултат от задължението му да изготвя като част от доклада за дейността си и нефинансова декларация съгласно Закона за счетоводството (Обн. ДВ. бр.95 от 8 Декември 2015г., посл. изм. и,доп. ДВ. бр.26 от 22 Март 2020г.). Предвид факта, че средносписъчния брой на персонала на ТЕЦ „Марица изток 2“ЕАД за 2019 г. е 2381 човека е удачно част от тази информация да бъде оповестена и на сайта на дружеството.

- По отношение на информацията за правата на човека

Дружеството оповестява подробна информация по отношение на правата на човека, което е резултат задължението му да изготвя като част от доклада за дейността си и нефинансова декларация. Предвид факта, че средносписъчния брой на персонала на ТЕЦ „Марица изток 2“ ЕАД за 2019 г. е 2381 човека е удачно част от тази информация да бъде оповестена и на сайта на дружеството.

\section{- По отношение на информацията за борбата с корупцията}

Подробна информация по отношение на извършваните дейности за борба с корупцията се съдържа единствено в доклада за дейността на дружеството., което е резултат задължението му да изготвя като част от доклада за дейността си и нефинансова декларация.

2.3. След изследване на годишния финансов отчет за 2019 г., годишния доклад за дейността и уеб сайта на „КонтурГлобал Марица изток 3“ АД за 2019 година се 


\section{установи че:}

- през 2019 година в годишния финансов отчет е оповестена информация за пет от седемнадесетте изследвани критерия. В годишния финансов отчет на „КонтурГлобал Марица изток 3“ АД са разкрити в стойностно изражение разходите за енергопотребление, за депониране на отпадъци, за закупуването на квоти и направените провизии, основно за посрещане на бъдещи задължения по възстановяване на земята, върху която са разположение съоръжения на централата (като сгуроотвала, складовите стопанства за въглища и мазут). Дружеството подробно информира за количеството въглероден диоксид, което емитира през годината и произлизащият от това излишък, съответно недостиг на квоти за емисия на парникови газове;

- За 2019 година в годишния доклад за дейността е оповестена информация за четири от седемнадесетте критерия. Като цяло може да се заключи, че „КонтурГлобал Марица Изток 3“ АД оповестява в годишния си доклад за дейността по-скоро нефинансова екологична информация - като разполагаема мощност и до каква степен е използвана през годината тя (в проценти). Дружеството съобщава на заинтересованите страни за наличие на екологична политика, която обосновава с притежавания стандарт ISO 14001. Но никъде в детайли не е оповестено в какво точно се изразява тази политика, налични ли са някакви системи за мониторинг и превенция на околната среда.

- През изследваният период в уеб сайта на дружеството (https://www.contourglobal.com/asset/maritsa-east-3) е оповестена информация за осем от седемнадесетте изследвани критерия. Следва да се отбележи, че предприятието няма собствен уеб сайт на български език, касаещ единствено оперираната от него електроцентрала. Информация за дружеството е поместена на интернет страницата на дружеството - майка Contur Global. Там е декларирано, че дейността на дъщерното й предприятието съответства на всички нормативни изисквания, като е уточнено, че през периода 2004 - 2009 година са направени мащабни реконструкции, целящи да се постигне съответствие на съоръжението с всички изисквания на Европейското законодателство и стандарти.

На интернет страницата може да се намери информация за някои основни екологични политики, като например грижа за и възстановяване на засегнатите горски масиви. Освен това са публикувани и годишни отчети за устойчиво развитие, в които има и информация, касаеща екологичното въздействие на оперираните съоръжения върху околната среда.

- По отношение на информацията за извършваните социални дейности

Публикувана е единствено на уеб сайта на дружеството, където са налични и отчети за устойчиво развитие. Като цяло има по-скоро описателен характер.

- По отношение на информацията за правата на овека

Публикувана е единствено на уеб сайта на дружеството, където са налични и отчети за устойчиво развитие. Като цяло има по-скоро описателен характер.

- По отношение на информацията за борбата с корупцията

Като цяло подобна информация не е налична.

Таблица 1. Сыпоставка на нивото на оповестяване на нефинансова информация в изследваните предприятия

\begin{tabular}{|c|c|c|c|c|}
\hline \multirow[b]{2}{*}{ Наличие на оповестяване в } & \multirow[b]{2}{*}{$\begin{array}{c}\text { уеб } \\
\text { сайт }\end{array}$} & \multicolumn{3}{|c|}{2019} \\
\hline & & ГДД & $\Gamma \Phi О$ & $\begin{array}{c}\text { верифици- } \\
\text { рани } \\
\text { доклади }\end{array}$ \\
\hline І. Информация с екологична насоченост & & & & \\
\hline
\end{tabular}


ИЗВЕСТИЯ НА СЬЮЗА НА УЧЕНИТЕ - ВАРНА

\begin{tabular}{|c|c|c|c|c|}
\hline $\begin{array}{l}\text { 1. Съответствие на осъществяваната дейност } \\
\text { със законовите изисквания }\end{array}$ & $1,2,3$ & 1,2 & & \\
\hline $\begin{array}{l}\text { 2. Предприети измервания за намаляване на } \\
\text { негативните последици върху околната среда }\end{array}$ & 1,2 & 1 & & \\
\hline $\begin{array}{l}\text { 3. Програми за опазване на околната среда и } \\
\text { сертифициране }\end{array}$ & $1,2,3$ & $1,2,3$ & & \\
\hline 4. Наличие на екологична политика & $1,2,3$ & $1,2,3$ & & \\
\hline 5. Инсталирана мощност & $1,2,3$ & $1,2,3$ & 1 & \\
\hline 6. Използвана мощност & 2 & $1,2,3$ & & \\
\hline 7. Енергийно потребление за определен период & & & 2,3 & \\
\hline 8. Горива за производство на електроенергия & 1,3 & 1,2 & $1,2,3$ & \\
\hline \multicolumn{5}{|l|}{ 9. Потреблението на вода } \\
\hline 10. Емисия вредни газове & & 1 & & $1,2,3$ \\
\hline 11. Отпадыци & 1,2 & 1 & 1,3 & \\
\hline $\begin{array}{l}\text { 12. Направени разходи и инвестиции за } \\
\text { превенция на негативни последици върху } \\
\text { околната среда }\end{array}$ & 1,2 & & & \\
\hline $\begin{array}{l}\text { 13. Сума на направени провизии и поети } \\
\text { гаранции във връзка с екологични рискове }\end{array}$ & & & $1,2,3$ & \\
\hline $\begin{array}{l}\text { 14. Сума на квотите, платени от дружеството по } \\
\text { време на упражняваната от него дейност за } \\
\text { нанесени вреди }\end{array}$ & & 1,2 & $1,2,3$ & \\
\hline 15. Екологични глоби и санкции & & 1 & 2 & \\
\hline \multicolumn{5}{|l|}{ 16. Компенсация на трети лица } \\
\hline $\begin{array}{l}\text { 17. Други показатели за екологично } \\
\text { представяне }\end{array}$ & 1,3 & & & \\
\hline \multicolumn{5}{|l|}{ II. Информация за социални дейности } \\
\hline $\begin{array}{l}\text { 1. Политика на осигуряване на здравословни и } \\
\text { безопасни условия на труд }\end{array}$ & 1,3 & 2 & & \\
\hline
\end{tabular}




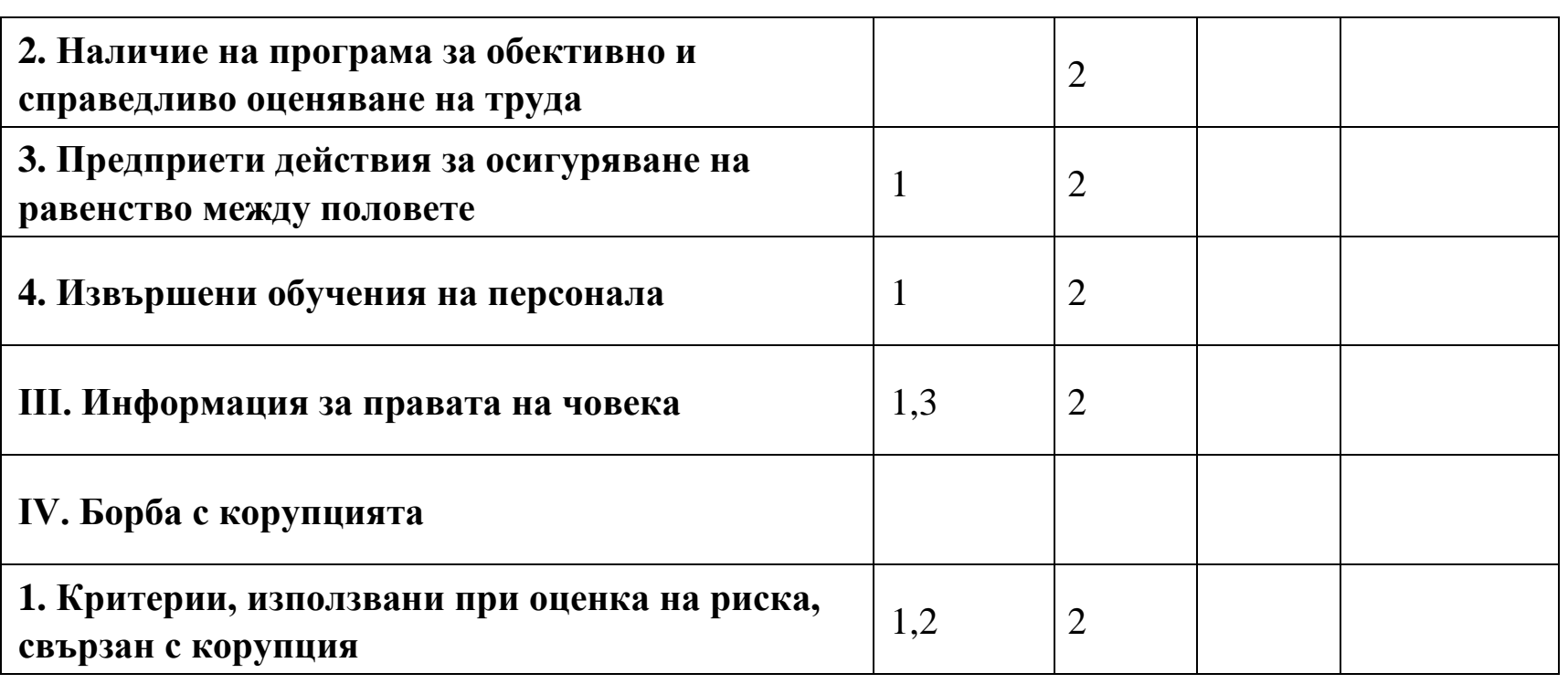

Като цяло в резултат на проучването може да се обобщи, че нито едно от дружествата не разкрива информация по критерия за изплатени компенсации на трети лица. Проучване в дружествата установи, че през периода такива не е имало, но независимо от това авторът поддържа мнението, че при нанасяне на екологични щети на външни лица, ако същите бъдат обезщетени за претърпените вреди, външните потребители трябва да бъдат информирани, което предполага в оповестяванията да има конкретен текст за наличието или липсата на такива.

По отношение на потреблението на енергия за производство, вода, горива, информация е разкрита основно в приложенията към годишните финансови отчети на дружествата и то най - често чрез паричен измерител. Добре би било да се посочват и използваните количества в съответните мерни единици, за да могат да се съпостяват употребените ресурси не само в стойностно изражение, доколкото по този начин ще се създадат предпоставки да се неутрализира влиянието на изменението на цените и външните потребители да добият представа за производствения капацитет на отделните предприятия.

Само две от дружествата разкриват информация за начислени от тях провизии за задължения с екологичен характер - ТЕЦ Марица Изток 2 ЕАД и КонтурГлобал Марица изток 3 АД. Те признават провизии за задължението си да закупят превишението над разпределените и закупени емисии за парникови газове за съответната година и провизии за задължението им да извършат технологична и биологична рекултивация на нарушените в резултат от дейността им терени. Впечатление прави, че в проучените предприятия е предпочитана политиката на текущо начисляване на разходи, но не и съобразяване с принципа на предпазливост и тяхното по-ранно предвиждане.

В изследвания период всяко от дружествата разкрива информация за направени разходи и инвестиции за превенция на оказваните негативни екологични ефекти. Това биват най - вече инвестиции в дълготрайни активи, които намаляват замърсяването, причинено от отделните топлоелектрически централи, най - характерни от които са сероочистващите инсталации, депа за рекултивация на отпадъците, разходи за очистване на водни обекти и ресурси и други. Това е един от критериите, по които е разкрита информация в най - голяма степен, както в годишните финансови отчети, така и в годишните доклади за дейността на предприятията. Аналогично са оповестени и данните за сумата на платените от дружествата квоти за емисии на парникови газове. Препорьчително е дружествата да оповестяват тази информация както количествено, така и стойностно, доколкото квотите за емисии са водещ показател за отрасъла, в който оперират и е желателно потребителите на информация да имат по-детайлна информация за извършеното от предприятието замърсяване. 
Впечатление прави също така, и ограничената информация по отношение на извършваните от дружествата социални дейности, за правата на човека и борбата с корупцията. Оказва се, че подобна информация се оповестява единствено, ако разкриването и се изисква по силата на нормативен акт.

\section{Заключение}

В заключение може да се обобщи, че топлоелектрическите централи в България оповестяват нефинансова информация основно в годишните доклади за дейността си и в уеб сайтовете си. В последните представят най-вече данни за наличието на политика по опазване на околната среда, предприети програми за опазването й и сертифициране на дружествата (основно по стандарт ISO 14 001), както и други показатели за екологичното и социалното им представяне като получени награди, отчети за устойчиво развитие и предстоящи екологични и социални проекти.

\section{References}

1. MOSV, Treti natsionalen plan za deystviye po izmeneniye na klimata za perioda 2013 - 2020 g., [Online] Available from: https://www.moew.government.bg/ static/media/ups/articles/ attachments/Treti_nacionalen_plan_za_deistvie_po_izmenenie_na_klimata986648423b859d321 7cae8640e285724.pdf [Accessed 20/11/2020]

2. Izpulnitelna agentsiya po okolna sreda, [Online] Available from: http://eea.government.bg/bg/rr/r-te/verifitsirani-dokladi-20/dokladi-1r [Accessed 20/11/2020]

3. Direktiva 2014/95/ES, obn. Ofitsialen vestnik na Evropeyskiya suyz, br.L330/1 ot 15.11.2014 g.

4. Turgovski registar, [Online] Available from: https://portal.registryagency.bg/ [Accessed 20/11/2020]

5. https://aes.bg [Accessed 20/11/2020]

6. Direktiva 2001/80/EC za ogranichavane na yemisiite, izpuskani ot golemite gorivni instalatsii, obn. Ofitsialen vestnik na Evropeyskiya suyz, br. L 309/1 ot 27.11.2001 g.

7. Direktiva 2010/75/ES, otnosno yemisiite ot promishlenostta (kompleksno predotvratyavane i kontrol na zam"rsyavaneto, obn. Ofitsialen vestnik na Evropeyskiya suyz, br. L 334/17 ot 17.12.2010 g..

8. https://www.tpp2.com/ [Accessed 21/11/2020]

9. Zakon za schetovodstvoto, Obn. DV. br.95 ot 8 Dekemvri 2015g., posl. izm. i,dop. DV. br.26 ot 22 Mart 2020g.

10. https://www.contourglobal.com/asset/maritsa-east-3 